\title{
International Journal of Clinical Cardiology
}

\section{A Rare Case of Syncope Secondary to Sinus Node Dysfunction Associated with Brugada Syndrome}

\section{Maya Khodor, $M D^{1^{*}}$ and Joseph Chattahi, $M D^{2}$}

${ }^{1}$ American University of Caribbean, USA

${ }^{2}$ Beaumont Hospital, Dearborn, Michigan, USA

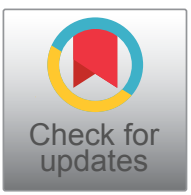

*Corresponding author: Maya Khodor, MD, American University of Caribbean, USA, Tel: 407-353-8875

\section{Keywords}

Brugada, Sinus node dysfunction, Syncope

\section{Introduction}

Brugada Syndrome is a rare arrhythmogenic entity that poses a risk of sudden cardiac death due to ventricular arrhythmias. Sinus node dysfunction is a less recognized and acknowledged conduction abnormality associated with Brugada syndrome, but nevertheless an important potential manifestation that can alter management. We present a case of a young patient who presented with syncope initially presumed to be secondary to a ventricular arrhythmia in the setting of newly diagnosed Brugada syndrome but was later found to have evidence of sinus node dysfunction. We review the relevant literature and discuss the management.

\section{Case Presentation}

A 31-year-old male with no significant past medical history presents after a witnessed syncopal episode. He denied any pre or post syncopal symptoms of chest pain, palpitations, fevers, nausea, loss of bowel or bladder control or tongue biting. He does not take any medications and denied any family history of sudden cardiac death. His physical exam and laboratory workup were unremarkable. His ECG showed sinus rhythm with coved ST segment elevation and T wave inversions in

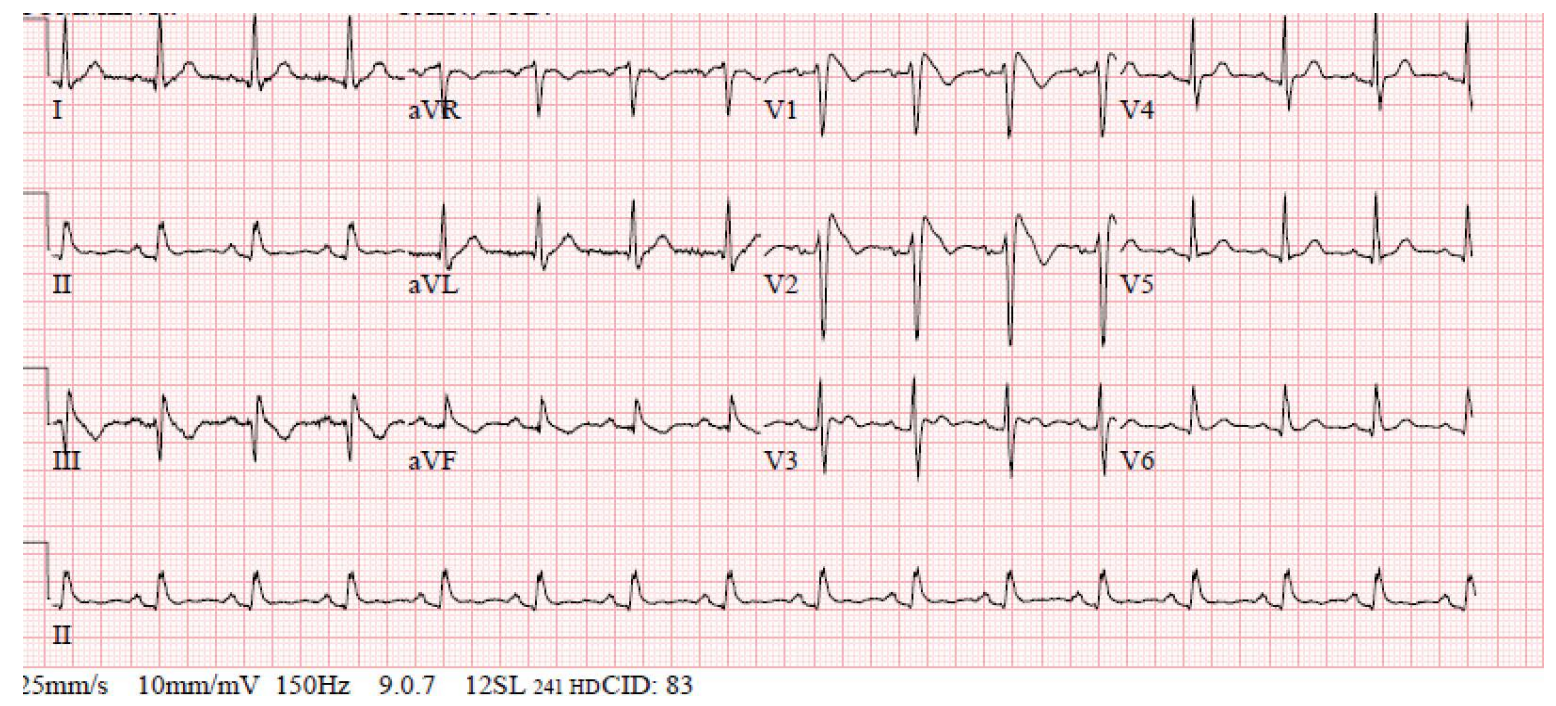

Figure 1: ECG with normal sinus rhythm and type-1 Brugada pattern.

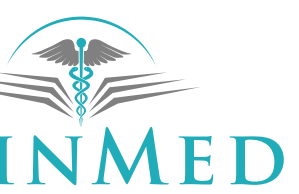

INTERNATIONAL LIBRARY
Citation: Khodor M, Chattahi J (2021) A Rare Case of Syncope Secondary to Sinus Node Dysfunction Associated with Brugada Syndrome. Int J Clin Cardiol 8:223. doi.org/10.23937/2378-2951/1410223 Accepted: April 22, 2021: Published: April 24, 2021

Copyright: (c) 2021 Khodor M, et al. This is an open-access article distributed under the terms of the Creative Commons Attribution License, which permits unrestricted use, distribution, and reproduction in any medium, provided the original author and source are credited. 
leads V1 and V2 consistent with type 1 Brugada pattern (Figure 1). His echocardiogram was unremarkable with normal chamber size, no hypertrophy or valvular disease and a left ventricular ejection fraction of $60 \%$. He was evaluated by general cardiology and electrophysiology and due to the concern for Brugada associated ventricular tachyarrhythmias as the culprit for his syncopal event, the placement of a defibrillator was recommended. After lengthy discussions with the patient about the different types of defibrillators, he elected to havea subcutaneous defibrillator (S-ICD) due to its cosmetic advantage, lack of vascular injury risk and low systemic infection risk (Figure 2). Unfortunately, after placement of his S-ICD, the patient had another syncopal episode associated with dizziness while he was in the hospital. The episode was documented on the telemetry monitor and revealed a 12 second sinus arrest (Figure 3A). The patient received brief CPR before regaining consciousness. Continuous telemetry monitoring revealed multiple episodes of sinus pauses of different durations at different times (Figure 3B). Multiple differential diagnoses were entertained including sinus node dysfunction in the setting of Brugada vs. vasovagal syncope. Due to concerns of recurrent episodes, the patient was presented with different management options including the placement of a pacemaker or a dual chamber ICD

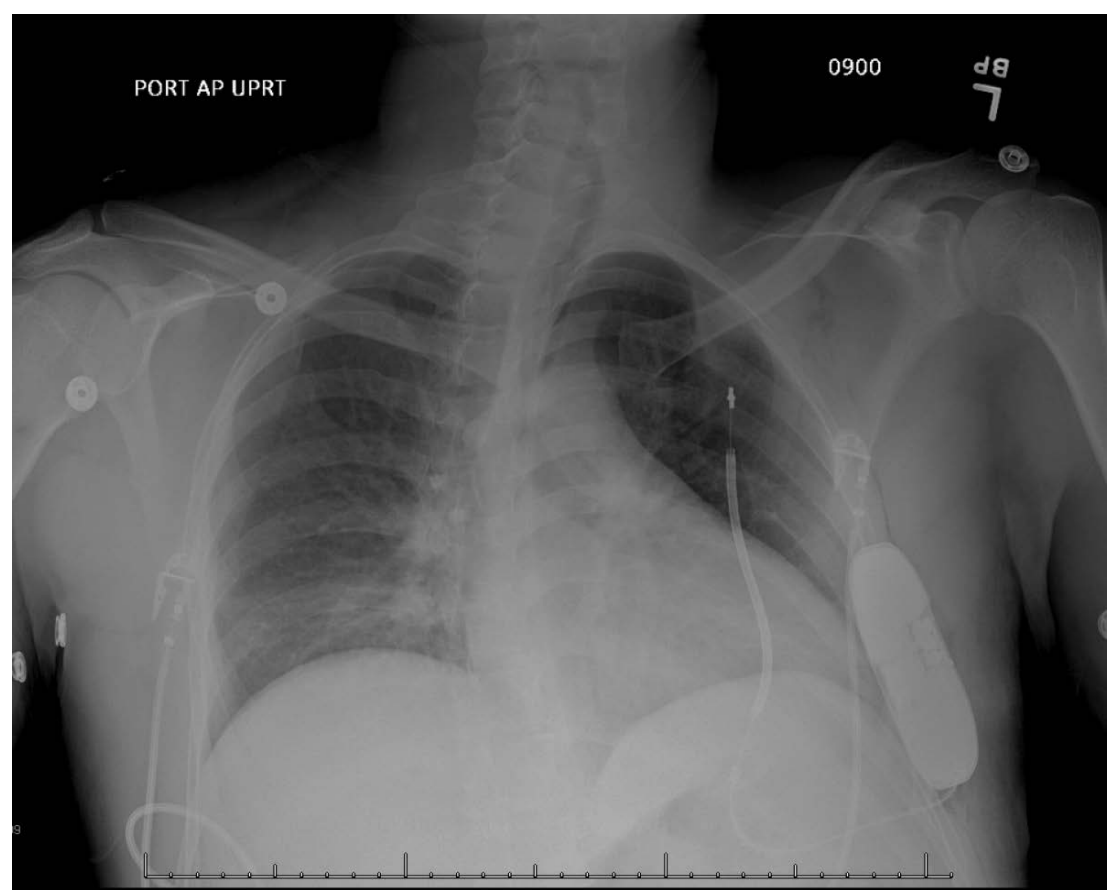

Figure 2: Chest X-ray status post subcutaneous ICD placement.

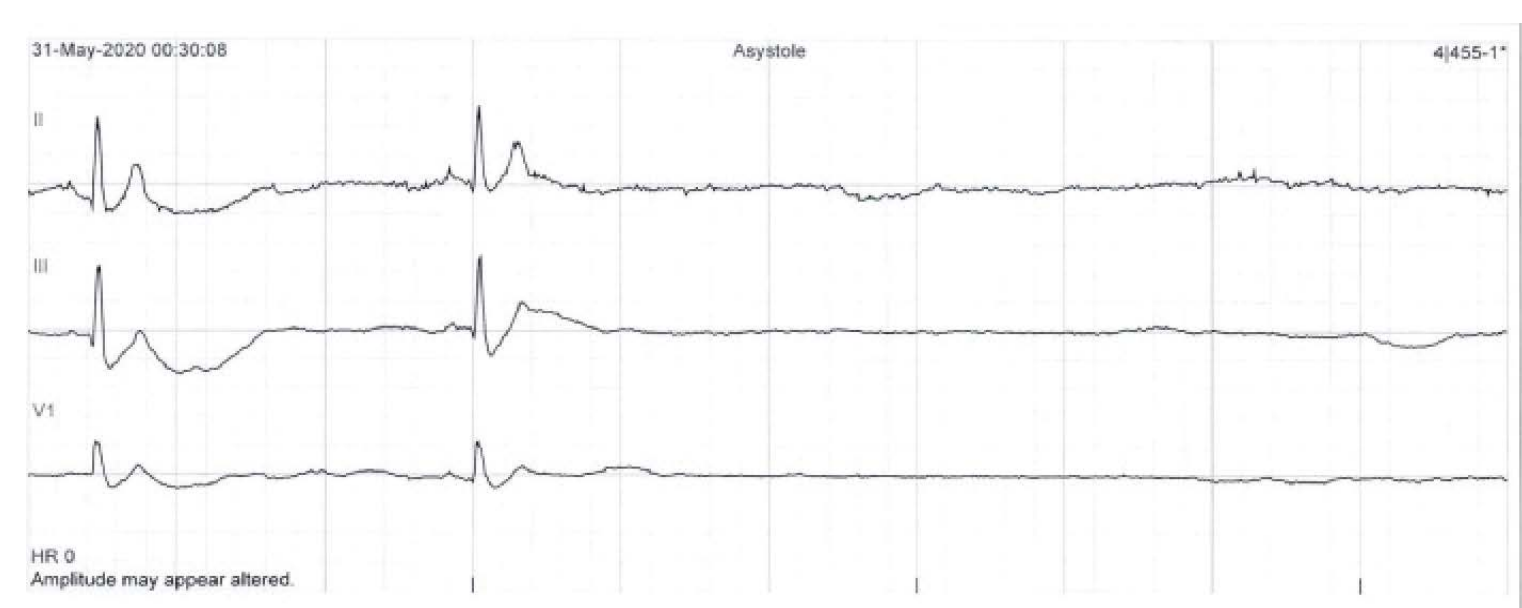

Notes :

ASYSTOLE RTT CALLED AT 0035

Figure 3A: In-hospital telemonitor demonstrates asystole during patient's syncopal episode. 

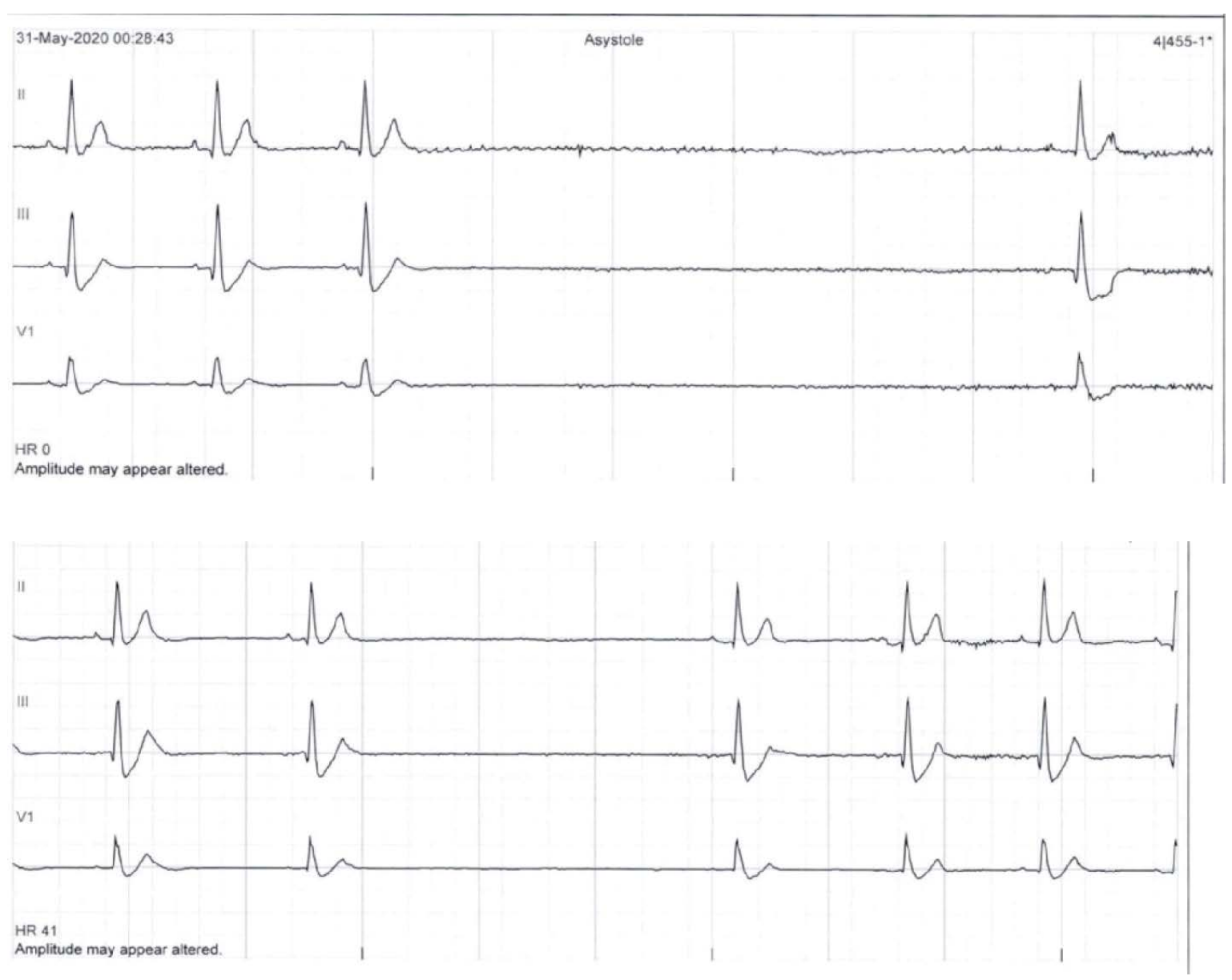

Figure 3B: In-hospital telemonitor demonstrates sinus pauses.

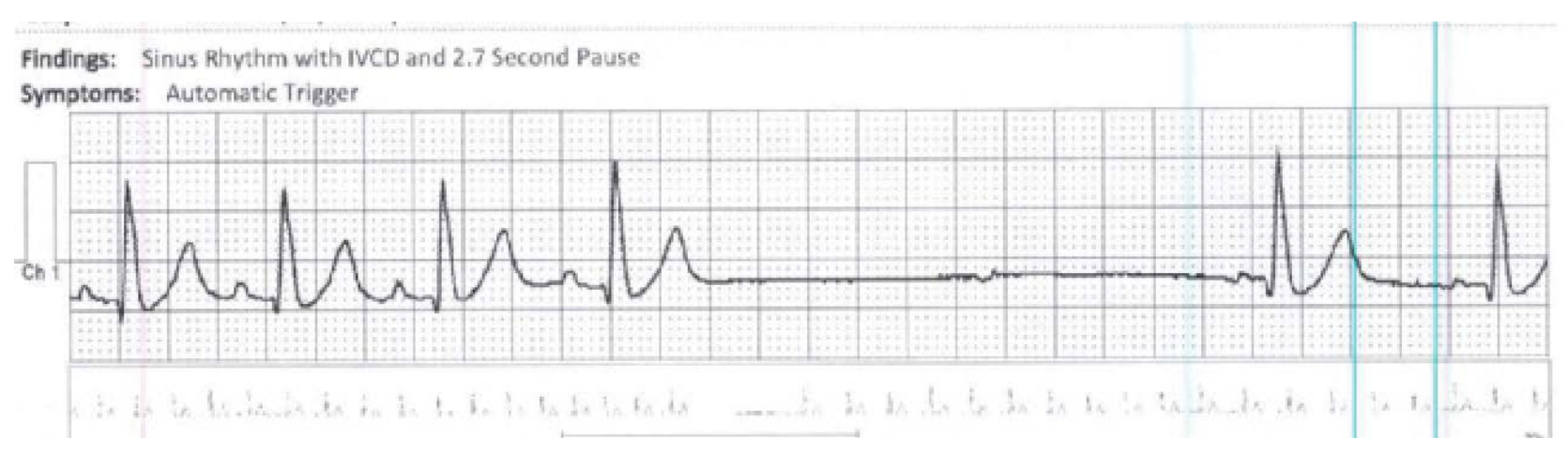

Figure 4: Holter monitor strip demonstrates sinus pause.

and the future removal of the subcutaneous ICD. Hedeferred further procedures and elected to pursueout patient cardiac event monitoring. He was scheduled to follow up in clinic with recommendation to obtain an outpatient cardiac MRI to rule out infiltrative diseases. He had a few more episodes of sinus pause documented and Mobitz $1 \mathrm{AV}$ block on his event monitor which he reported were not associated with any syncopal events (Figure 4).

\section{Discussion}

Brugada syndrome (BrS) is a well-known arrhythmogenic entity associated with a risk of sudden cardiac dea- th $(S C D)$ due to ventricular fibrillation. It is characterized by a pseudo-right bundle branch block pattern on ECG with ST elevations in V1 and V2 that are either "coved" as in type 1 or "saddle back" as in type 2 (Figure 1). The diagnosis of a syndrome is made based on the presence of the ECG pattern and the clinical presentation which may manifest assyncope or SCD; classically attributed to ventricular arrhythmias and specifically polymorphic ventricular tachycardiac originating from the right ventricular outflow tract [1]. Supraventricular tachycardia and atrial fibrillation have been linked to $\mathrm{BrS}$ with an estimated incidence of $10-13 \%$ [1-3]. Sinus node dysfunction (SND) in patients with Brugada has also been described and reported in the literature; but remains 
clinically a less recognized and identified presentation.

In 2005, evidence of SND in a young patient with BrS who died suddenly was illustrated on autopsy which revealed deposition of fatty tissue, atrophy and fibrosis of the sinus node [4]. A study by Bordachar, etal. of 59 asymptomatic patients demonstrated that $17 \%$ of them had SND induced during electrophysiology study [2]. Clinically documented SND in patients with $\mathrm{BrS}$ was estimated to be $1.1-1.7 \%$ in large population studies $[5,6]$. The prevalence of SND in children with $\mathrm{BrS}$ was higher than that in adults reaching 7.5\%-9.0\% $[7,8]$.

Up to 20 different genetic mutations have been associated with $\mathrm{BrS}$, including mutations in genes encoding sodium channel, calcium channels and potassium channels, and proteins affecting ion channels [9].Interestingly, mutations in the cardiac predominant sodium channel $\alpha$-subunit SCN5A which accounts for $20-30 \%$ of patients with Brugada, has been linked to SND [9-12]. The abnormal sodium channel is thought to prolong the action potential of sinus node cells, slow depolarization and as a result contribute to SND [13]. An overlap syndrome of cardiac sodium channelopathy including $\mathrm{BrS}$, conduction disease and long QT syndrome has been proposed and linked to mutations in the gene encoding for SCN5A $[14,15]$.

SND has been identified in patients with $\mathrm{BrS}$ as a risk factor for arrhythmic events $[5,6]$. In a study of 116 adult family members of whom 60 of them were carriers of a mutant SCN5A gene, a possible bradycardic mode of death was suggested with a carrier of the gene who suffered from sinus arrest $>9$ seconds [13]. Although we are unable to determine the underlying rhythm that lead to our patient's first out-of-hospital syncopal event, his subsequent in-hospital syncopal event was due to a recorded 12 second sinus arrest. In fact, the patient proceeded to have multiple more episodes of sinus pausethat were documented during his hospital stay and after discharge. Unfortunately, these episodes were identified after his subcutaneous ICD was already placed for a presumed ventricular arrhythmogenic cause of his presenting syncope. The patient declined pacemaker placement during the index hospitalization and elected to continue to monitor his rhythm and symptoms using an event monitor and to further discuss the placement of a pacemaker in the outpatient setting. The recognition of the possible overlap of BrS and SND is important in management and decision making. Given this association, we recommend avoiding the placement of SQ ICD which may necessitate future procedures such as the placement of a pacemaker or transvenous ICD and the removal of SQ ICD in the event that sinus node dysfunction is to develop.

\section{Conclusion}

Sinus node dysfunction is an underrecognized entity in patients with Brugada syndrome or pattern. It is imperative that providers and cardiologists are aware of this association which is likely related to common genetic mutations leading to an overlap syndrome.Consideration of SND in patient with BrS should be taken into account when making decisionsinregard tomanagement and device therapy.

\section{Sources of Funding}

None.

\section{Disclosures}

We have no relationship with industry to declare.

All authors contributed to the writing and review of the manuscript.

\section{References}

1. Eckhardt LL (2016) Monomorphic ventricular tachycardia in Brugada syndrome: True-true but related? Hear Rhythm 13: $683-685$

2. Bordachar $P$, Reuter $S$, Garrigue $S$, Cai $X$, Hocini $M$, et al. (2004) Incidence, clinical implications and prognosis of atrial arrhythmias in Brugada syndrome. Eur Heart $\mathrm{J} 25$ : 879-884.

3. Morita H, Kusano-Fukushima K, Nagase S, Fujimoto Y, Hisamatsu K, et al. (2002) Atrial fibrillation and atrial vulnerability in patients with Brugada syndrome. J Am Coll Cardiol 40: 1437-1444.

4. Morimoto SI, Uemura A, Hishida H (2005) An autopsy case of Brugada syndrome with significant lesions in the sinus node. J Cardiovasc Electrophysiol 16: 345-347.

5. Sieira J, Conte G, Ciconte G, Asmundis C, Chierchia G-B, et al. (2016) Clinical characterisation and long-term prognosis of women with Brugada syndrome. Heart 102: 452-458.

6. Sieira J, Ciconte G, Conte G, Chierchia G-B, Asmundis C, et al. (2015) Asymptomatic Brugada syndrome: Clinical characterization and long-term prognosis. Circ Arrhythm Electrophysiol 8: 1144-1150.

7. Conte G, Dewals W, Sieira J, Asmundis C, Ciconte G, et al. (2014) Drug-induced Brugada syndrome in children: Clinical features, device-based management, and long-term follow-up. J Am Coll Cardiol 63: 2272-2279.

8. Gonzalez Corcia MC, Sieira J, Pappaert G, Asmundis C, Chierchia GB, et al. (2017) A clinical score model to predict lethal events in young patients ( $\leq 19$ years) with the Brugada syndrome. Am J Cardiol 120: 797-802.

9. Watanabe H, Minamino T (2016) Genetics of Brugada syndrome. J Hum Genet 61: 57-60.

10. Makiyama T, Akao M, Tsuji K, Doi T, Ohno S, et al. (2005) High risk for bradyarrhythmic complications in patients with Brugada syndrome caused by SCN5A gene mutations. J Am Coll Cardiol 46: 2100-2106.

11. Grant AO, Carboni MP, Neplioueva V, Starmer CF, Memmi $\mathrm{M}$, et al. (2002) Long QT syndrome, Brugada syndrome, and conduction system disease are linked to a single sodium channel mutation. J Clin Invest 110: 1201-1209.

12. Smits JPP, Koopmann TT, Wilders R, Veldkamp MW, Opthof $\mathrm{T}$, et al. (2005) A mutation in the human cardiac sodium channel $(\mathrm{E} 161 \mathrm{~K})$ contributes to sick sinus syndrome, conduction disease and Brugada syndrome in two families. $J$ Mol Cell Cardiol 38: 969-981. 
13. Berg MP, Wilde AA, Viersma TJW, Brouwer J, Haaksma $\mathrm{J}$, et al. (2001) Possible bradycardic mode of death and successful pacemaker treatment in a large family with features of long QT syndrome type 3 and Brugada Syndrome. $\mathrm{J}$ Cardiovasc Electrophysiol 12: 630-636.

14. Remme CA, Verkerk AO, Nuyens D, Ginneken ACG, Brun- schot S, et al. (2006) Overlap syndrome of cardiac sodium channel disease in mice carrying the equivalent mutation of human SCN5A-1795insD. Circulation 114: 2584-2594.

15. Makita N (2009) Phenotypic overlap of cardiac sodium channelopathies: Individual-specific or mutation-specific? Circ J 73: 810-817. 